\title{
Royal Society of Medicine
}

Mrs. Ewing : That was up to twenty-five years of age.

Dr. EwING went on to say that with regard to the whole question of the education of the deaf the economic factor had to be considered. They had to be taught in special schools and that meant that where the schools were residential an artificial community was created. If the communication between the children in the schools lasted over a longer period than their communication with people outside a form of mental inbreeding took place.

The problem seemed to be indicated on these lines: physically the effects of deaf-mutism were not very grave, but they were most serious in the deprivation of opportunity. It was very important to incorporate the deaf as far as possible in normal life and activities and there the otologist could be of great assistance in bridging the gap.

\section{LETTER TO THE EDITOR}

To THE EDITOR,

The Journal of Laryngology and Otology.

MALIGNANT MELANOMA OF PALATE AND FAUCES

DEAR SIR,-With regard to the record of the case of a woman of 43 that you published for me under the above title in the January issue, my attention has been called to the fact that there was no specific mention of the pathologist's report. Sections were examined by two pathologists who both agreed as to the malignant nature of the tumour. Furthermore, I have just heard that a week ago the patient unfortunately died with secondary melanotic deposits in the liver but no sign of local recurrence.

WALTER Howarth. 